\title{
The Effect of Low Frequency and Direct Current Stimulation on The Kindling Phenomenon in Rats
}

\author{
JOHN GAITO
}

SUMMARY: An experiment was conducted to evaluate the effect of $1-\mathrm{Hz}$ or direct current brain stimulation on kindling behavior induced by $60-\mathrm{Hz}$ sine wave stimulation. The effective threshold intensity to elicit a convulsion was determined on four separate occasions with 5 days of daily trials between determinations. On each day one group of experimental rats was stimulated with $\mathrm{l}-\mathrm{Hz}$ sine wave current before and after stimulation with $60-\mathrm{Hz}$ sine wave current (1-60-1 group). Another group received direct current stimulation and $60-\mathrm{Hz}$ current (D-60-D group). A third group received only $60-\mathrm{Hz}$ stimulation. Suppression of kindling behavior usually induced by the 60- Hz stimulation occurred

RESUMÉ: Nous avons effectué une expérience dans le but d'évaluer l'effet de stimulations cérébrales de $\mathrm{I}-\mathrm{Hz}$ ou de courant direct sur le comportement Kindling induit par une stimulation sinusoidale de 60-Hz. Le seuil d'intensité efficace pour produire une convulsion fut déterminé en quatre occasions différentes séparées par 5 jours d'essais quotidiens entre les déterminations. Chaque jour un groupe de rats expérimentaux fut stimulé avec un courant sinusoidal de l-Hz avant et après la stimulation au courant sinusoidal de $60-\mathrm{Hz}$ (groupe l-60-1). Un deuxième groupe reçut une stimulation au courant direct et un courant direct de 60- $\mathrm{Hz}$ (groupe $\mathrm{D}-60-\mathrm{D}$ ). Un troisième groupe ne reçut que la stimulation de 60- $\mathrm{Hz}$. La suppression du comportement Kindling généralement causé with $\mathrm{l}-\mathrm{Hz}$ stimulation; the mean threshold value increased on each successive determination. Suppression was most pronounced for the direct current group; it appeared after a single trial and persisted for 32 days after the last threshold determination. In contrast, most of the rats in the I-60-I group had recovered from the suppression after the 32 day period of nonstimulation. A second phase of the experiment indicated that the increase in threshold values for the D-60-D group occurred after a single DC stimulation. These results are consistent with the hypothesis generated by previous research that suppression following $\mathrm{l}-\mathrm{Hz}$ stimulation is not due to tissue damage.

par la stimulation $60-\mathrm{Hz}$ se produisit avec la stimulation $1-\mathrm{Hz}$; la valeur moyenne $d u$ seuil augmentant à chaque détermination successive. L'effet suppresseur fut le plus marqué dans le groupe à courant direct; il apparaissait dès le premier jour et persistait 32 jours après la dernière détermination de seuil. Par contre, la plupart des rats du groupe 1-60-I récupéraient de l'effet suppresseur après une période de 32 jours de non stimulation. Une deuxième phase de l'expérience indique une augmentation des valeurs du seuil du groupe 0-60-D après une simple stimulation $D C$. Ces résultats sont compatibles avec l'hypothèse préalablement exprimée qui veut que l'effet suppresseur suivant une stimulation de 1 $\mathrm{Hz}$ n'est pas due à une lésion tissulaire.

\section{INTRODUCTION}

The "kindling effect" has been investigated in a number of laboratories (e.g., Gaito, 1976b; Goddard, et al., 1969; Racine, 1972; Wada and Sato, 1975). In rats it involves a change from normal exploration (Stage 1) to behavioral automatisms (Stage 2 chewing, eye closure on ipsilateral side, salivation), and finally to clonic convulsions (Stage 3 ) in response to electrical stimulation of a specific brain site (e.g., amygdala). During Stage 3 the rat stands on its hind paws and bilateral convulsions of the forelimbs occur. A kindling progression occurs also in other animals, viz., frog, reptile, mouse, rabbit, cat, monkey, and baboon (Racine, 1978). A permanent change that does not damage tissue is assumed to occur in the brain during kindling (Goddard et al., 1969; Racine, 1978). Behavioral, chemical, electrophysiological, and neurological aspects of this effect have been investigated previously (Gaito, 1976a; Racine, 1978).

We attempted to determine sine wave frequencies which might interfere with the production of convulsions by $60-\mathrm{Hz}$ sine wave stimulation. In a series of experiments $3-\mathrm{Hz}$ stimulation consistently produced an interference effect, i.e., suppression of convulsions (Gaito, 1979a,b; Gaito, et al., 1980). Another experiment evaluated the effect of varying durations of $1-\mathrm{Hz}$ stimulation, viz., $0,5,15,30,60,120$, 180 , and 600 seconds (Gaito, 1980a). The 5 second condition gave the same results as the control condition $(0$ seconds stimulation) - there was no interference effect. With 15 seconds of stimulation there was a minor effect. The effect was more pronounced at 30 seconds. The 60,120 and 180 seconds 
of stimulation produced severe effects. The greatest effect was with the 600 second stimulation period. The overall result was that of an increasing suppression effect as duration of stimulation increased. Similar results occurred with $3-\mathrm{Hz}$ stimulation (Gaito, 1980b).

In other experimentation it was found that interference or suppression varies with remoteness from the kindling frequency. The least interference occurred with $60-\mathrm{Hz}$ stimulation and the greatest, with $\mathrm{I}-\mathrm{Hz}$ current; $30-$ $\mathrm{Hz}, 10-\mathrm{Hz}$, and $5-\mathrm{Hz}$ stimulation produced intermediate degrees of interference (Gaito, 1980c).

It is possible that suppression occurs as a result of tissue damage, although this seems unlikely since the suppression effect disappears in most rats after 15 to 18 days without stimulation. (Gaito, 1980a; Gaito, Nobrega, and Gaito, 1980). Yet low frequency sine waves (1and $3-\mathrm{Hz}$ ) are not too dissimilar from direct current, which does produce tissue damage. Thus the present experiment was designed to contrast the effect on the kindling phenomenon of both direct current and $1-\mathrm{Hz}$ stimulation.

\section{METHODS}

Thirty male Wistar rats (approximately 150 days of age) had nichrome bipolar electrodes implanted unilaterally in the amygdala. The brain coordinates for electrode implantation were the same as in many experiments in our laboratory: $.5 \mathrm{~mm}$ posterior to bregma, $4.5 \mathrm{~mm}$ from midline, $8.5 \mathrm{~mm}$ from skull (Gaito, 1976b).

Stimulation was not imposed until at least 7 days after surgery. Then the 30 rats were stimulated with $60-\mathrm{Hz}$ sine waves for 30 seconds during three trials on the first day. One hour intervened between each trial. A Lafayette Stimulator was used; the intensity was $36 \mu \mathrm{A}$ (root mean square, RMS). On the first trial of the second day the effective threshold intensity $\left(\mathrm{ETl}_{1}\right)$ was determined. The $60-\mathrm{Hz}$ current was increased until a Stage 2 or 3 response was elicited. Then $5 \mu \mathrm{A}$ was added to allow for day-by-day threshold fluctuations. Two further trials of stimulation at this intensity were provided to check for consistency.
The 30 rats were separated into 10 sets of triplets based on the values of ETI $_{1}$. Within each triplet the ETI, value was approximately the same. Each of the rats in the triplets was randomly assigned to one of the three groups. One group of 10 rats received stimulation with $1-\mathrm{Hz}$ sine waves for 60 seconds on Trials 1 and 3 each day for 5 days at twice the $\mathrm{ETI}_{1}$ value. A $60-\mathrm{Hz}$ stimulation trial was provided on Trial 2 for 30 seconds at $\mathrm{ETI}_{1}$ (Group 1, 1-60-1). There was one hour between each trial. The second group of 10 rats was stimulated with direct current (DC) for 60 seconds at double the $\mathrm{ETI}_{1}$ value on Trials 1 and 3 and with $60-\mathrm{Hz}$ sine wave current on Trial 2 for 30 seconds at $\mathrm{ETI}_{1}$ (Group 2: D$60-D)$. Ten other rats received $60-\mathrm{Hz}$ stimulation on Trial 2, but on Trials 1 and 3 each rat was placed in the apparatus without stimulation (Group $3, \mathrm{X}-60-\mathrm{X})$. All $60-\mathrm{Hz}$ stimulation on Trial 2 was at ETI ${ }_{1}$ for 30 seconds, a duration which has been used routinely in our research. Stimulation on Trials 1 and 3 was for 60 seconds duration at two times $\mathrm{ETI}_{1}$; in previous experiments, this duration and intensity was found to produce a pronounced suppressive effect. The intensity of stimulation for any rat on these or later trials never exceeded $200 \mu \mathrm{A}$ (RMS), an upper limit which has been used consistently in our laboratory.

Following this 5 day period, rats from all groups had $\mathrm{ETI}_{2}$ determined over six trials during two days. Then another 5 day block of stimulation occurred in which each group was treated in the same manner as during the 5 day block of trials prior to the $\mathrm{ETI}_{2}$ determination. This pattern of alternating ETI determinations and a 5 day block of trials was continued through the $\mathrm{ETl}_{4}$ determination. All rats were then rested for 32 days and $\mathrm{ETI}_{5}$ was determined on one trial.

After completing this portion of the experiment, a second phase was instituted to evaluate the daily changes in ETI values during one block of trials. The 10 rats from the $1-60-1$ and $\mathrm{X}-60-\mathrm{X}$ groups were provided with three trials on one day to determine the threshold $\left(E T I_{1}\right)$. Based on this determination, 9 rats from each of the two groups were assigned to new D-60-
D, 1-60-1, and X-60-X groups while maintaining approximately the same mean ETI values for the three groups, except that slightly greater intensities were allowed for the X-60-X group. There were 6 rats in each new group. Then one block of trials over five days was initiated. The procedures paralleled those in Phase 1 except for the second trial of each day. This trial was with 60$\mathrm{Hz}$ stimulation, but a new threshold value was determined on each of the five days $\left(\mathrm{ETI}_{2}\right.$ through $\left.\mathrm{ETI}_{6}\right)$. $\mathrm{ETI}_{7}$ was determined on one trial on the next day.

Following most previous experiments, histological analyses had been performed on all rats. No gross lesions were detected for 1-60-1 and X-60-X rats at intensities of $200 \mu \mathrm{A}$ (RMS) and below (intensities used routinely in our experiments). The tissue around the electrode tips of rats stimulated with $1-\mathrm{Hz}$ or $\mathrm{1}-\mathrm{Hz}$ and $60-\mathrm{Hz}$ current was indistinguisable from that of rats stimulated only with $60-\mathrm{Hz}$ current. In the present experiment, histological analyses were conducted at the end of Phase 1 with all DC rats. Three rats which had received $\mathrm{l}-\mathrm{Hz}$ stimulation in both phases, and three animals in the $\mathrm{X}-60-\mathrm{X}$ group in both phases, were evaluated after Phase 2. Each was sacrificed with an overdose of sodium pentobarbital and perfused with saline and formalin. The brains were extracted and placed in a $10 \%$ formalin solution. Each brain was frozen and 50 micron sections were mounted on microscopic slides. The slides were placed in a photographic enlarger and used to obtain information concerning electrode site and the presence or absence of lesions around electrode tips. The enlargement was approximately ten-fold. A Luxo magnifier with a lens providing approximately double enla rgement was mounted over the microtome so that the electrode tips and the electrode track could be observed during the procurement of each tissue section. Continuous viewing of the tissue greatly increased the efficiency of the histological analyses.

In the tissue analyses, a 4 point scale was used to evaluate the tissue damage and progressed from 1 (definite lestion) through 4 (nonlesion appear- 
ance). The tissue at the electrode tips was viewed for the presence or absence of lesion characteristics, specifically, a hole at the site.

\section{RESULTS}

The gross histological analyses for the $10 \mathrm{DC}$ rats suggested a lesion or probable lesion in $9 ; 6$ had a score of 1 (definite lesion), 3 had a 2 (probable lesion), and 1 had a 3 (probable nonlesion). The analyses for the 1-60-1 and X-60-X group showed a score of 4 (nonlesion appearance) for all rats evaluated. Analyses in previous experiments had indicated similar results with $1-60-1$ and $X-60-X$ rats.

Neither the 1-60-1 nor the D-60-D groups showed the usual kindling progression prominent in X-60-X rats. No Stage 2 or 3 behaviour occurred in response to either $\mathrm{I}-\mathrm{Hz}$ or DC current stimulation.

The usual dependent variables, ETI and Composite Score, were used in the present experiment. With the latter measure, a score of 1 denotes Stage 1 behavior, 2, a Stage 2 response, and 3, a clonic convulsion. Any rat showing a Stage 1 response at the upper limit of $200 \mu \mathrm{A}$ was assigned a score of $208 \mu \mathrm{A}$ for that and later ETI determinations and was not used for the remaining block of trials. The results are shown in Table 1. The control rats, those subjected to no stimulation on Trials 1 and 3 (X-60-X group), showed a gradual decrease over the four determinations. The 1-60-1 group had the gradual increments over ETI determinations, typical of rats stimu- lated with $1-\mathrm{Hz}$ or $3-\mathrm{Hz}$ sine waves in previous experiments.

The suppression produced during Block 1 stimulation by DC current was quick and very severe. The mean ETI value was beyond the upper limit of $200 \mu \mathrm{A}$ for the D-60-D group. On Trial 1,9 of the 10 rats showed Stage 1 behavior, a $90 \%$ suppression rate. Suppression was complete for all rats on Trial 2 and for the remaining 3 days. During the $\mathrm{ETI}_{2}$ determination, 9 rats had Stage 1 behavior at the upper limit of $200 \mu \mathrm{A}$ and were not used in Block 2 trials. Thus, the mean value was beyond the upper limit of $200 \mu \mathrm{A}$. The tenth rat had Stage 1 responses during the $\mathrm{ETI}_{3}$ determination. These suppression results are much stronger than any encountered previously in our research.

A few rats in the 1-60-1 group showed Stage 1 behavior for ETI ${ }_{2}$ and later determinations at $200 \mu \mathrm{A}$ and were not used thereafter until the $\mathrm{ETI}_{5}$ determination; there was one rat for the $\mathrm{ETI}_{2}$ determination, two others for the $\mathrm{ETI}_{3}$ determination, and a fourth rat during the $\mathrm{ETI}_{4}$ event. The $\mathrm{ETI}_{1}$ value for the one rat which showed Stage 1 behavior on the $\mathrm{ETI}_{2}$ determination was $170 \mu \mathrm{A}$, which was very close to the upper limit.

The Mean Composite Score over three blocks of trials also showed the suppression effect (Table 2). The minimum and maximum scores, respectively, for Composite Score over 5 trials are 5 and 15 . Each rat received a score of 1 for Stage 1 behavior, a score of 2 for Stage 2 responses, and a value

TABLE 1

Mean ETI Values and Recovery Rates for the Three Groups of Ten Rats

\begin{tabular}{|c|c|c|c|c|c|c|}
\hline \multicolumn{7}{|c|}{ ETI Determinations } \\
\hline Group & 1 & 2 & 3 & 4 & 5 & Recovery Rate (\%) \\
\hline$X-60-X$ & 108 & 86 & 78 & 68 & 65 & 80 \\
\hline $1-60-1$ & 111 & 149 & 171 & 182 & 114 & 70 \\
\hline D-60-D & 100 & 205 & 208 & 208 & 207 & 00 \\
\hline
\end{tabular}

Some rats showed a Stage 1 response at $200 \mu \mathrm{A}$; a score of 208 was assigned to each of these rats. These were, 1-60-1 group: 1 rat, $\mathrm{ETl}_{2}-4$ rats, $\mathrm{ETI}_{3}$; D-60-D group: 9 rats, $\mathrm{ETI}_{2}-10$ rats, $\mathrm{ETI}_{3}, \mathrm{ETI}_{4}-9$ rats, $\mathrm{ETI}_{\mathrm{s}}$. All ETI values are in microamperes, root mean square (RMS).

Recovery rate refers to the percentage of rats which had non-Stage 1 behavior during the ETl, determination at approximately the previous low ETI determination value. of 3 for each convulsion. The X-60-X group had the usual kindling progression over the three blocks of trials with most rats showing Stage 3 behavior during Block 3. The 1-60-1 group had Mean Composite scores which were at the boundary of Stage 1 and 2 and did not show a kindling progression. The D-60-D group had a mean score indicating early Stage 1 behavior.

TABLE 2

Mean Composite Score

$\begin{array}{lrrr} & \text { Blocks of Trials } \\ \text { Group } & 1 & 2 & 3 \\ \text { X-60-X } & 10.2 & 12.7 & 14.0 \\ 1-60-1 & 8.3 & 9.5 & 8.8 \\ \text { D-60-D } & 5.1 & 5.6 & 5.0\end{array}$

Table 3 shows the Mean Composite Score for the five days of trials within each block. The minimum and maximum scores, respectively, for each trial and each rat is 1 and 3 . The $\mathrm{X}-60-\mathrm{X}$ group shows the usual gradual increase over trials until most rats are showing a convulsion on Day 5 of Block 3. The 1-60-1 group shows the opposite pattern (as in previous experiments). There is a gradual decline over trials. On Day 5 of each block the mean response is below that of Stage 2. A severe suppression effect is present for the D-60-D group which goes from a beginning Stage 2 response to a beginning Stage 1 response on Trial 1. Nine of ten rats had a Stage 1 response. By Trial 2, all rats showed Stage 1 behavior. Thus a single trial of DC current (Day 1) produced a drastic effect, whereas 1$\mathrm{Hz}$ stimulation required a number of trials to bring forth a pronounced effect.

Not a single rat from the D-60-D group recovered from the effect of the DC current after 32 days of nonstimulation. On the $\mathrm{ETI}_{5}$ determination at the upper limit of $200 \mu \mathrm{A}$, nine of the ten rats had a Stage 1 response while the tenth showed Stage 2 behavior. The mean of $207 \mu \mathrm{A}$ for this group was well above the $100 \mu \mathrm{A}$ for the $\mathrm{ETI}_{1}$ determination. 
TABLE 3

Mean Composite Score Within Blocks

\begin{tabular}{|c|c|c|c|c|c|c|c|c|c|c|c|c|c|c|c|c|c|c|c|c|c|}
\hline \multirow[b]{2}{*}{ Group } & & & $\begin{array}{c}1 \\
\text { Days }\end{array}$ & & - & & & & & & $\begin{array}{l}\text { ocks } \\
2 \\
\text { ays }\end{array}$ & & & & & & & $\begin{array}{l}3 \\
\text { ays }\end{array}$ & & & \\
\hline & o & 1 & 2 & 3 & 4 & 5 & M & O & 1 & 2 & 3 & 4 & 5 & M & 0 & 1 & 2 & 3 & 4 & 5 & $\mathbf{M}$ \\
\hline$X-60-X$ & 2.0 & 2.0 & 2.0 & 2.0 & 2.1 & 2.1 & 2.0 & 2.4 & 2.5 & 2.5 & 2.5 & 2.6 & 2.6 & 2.5 & 2.8 & 2.8 & 2.8 & 2.8 & 2.8 & 2.8 & 2.8 \\
\hline $1-60-1$ & 2.0 & 1.9 & 1.8 & 1.5 & 1.6 & 1.5 & 1.7 & $2.3^{*}$ & 2.3 & 2.2 & 2.0 & 1.6 & 1.9 & 1.9 & $2.8^{* *}$ & 2.7 & 2.8 & 2.2 & 1.8 & 1.8 & 2.3 \\
\hline D-60-D & 2.1 & 1.1 & 1.0 & 1.0 & 1.0 & 1.0 & 1.0 & + & & & & & & & + & & & & & & \\
\hline
\end{tabular}

0 , last trial of the previous ETI determination.

$M$, mean score per trial in each block of 5 trials.

* One rat had Stage I behavior at $200 \mu \mathrm{A}$ and was not used during Block 2 and 3 trials; thus, $n=9$ during Block 2 trials.

** Three rats had Stage 1 behavior at $200 \mu \mathrm{A}$ and were not used during Block 3 trials; thus, $\mathrm{n}=6$ during Block 3 trials.

+ Only one rat showed non-Stage 1 behavior and was used during Block 2 trials. This rat had a convulsion at $180 \mu \mathrm{A}$ during the ETI, determination and on Trials 1 to 3. On Trials 4 and 5 a Stage 1 response occurred. This rat also showed Stage I behavior during the $\mathrm{ETl}_{3}$ determination and was not used for Block 3 trials.

By contrast, and consistent with previous results, most of the 1-60-1 rats recovered from the suppression effect after the 32 days. Seven of the rats $(70 \%)$ were at about the $\mathrm{ETI}_{1}$ value. The mean for $\mathrm{ETI}_{5}$ was approximately the same as that for the $\mathrm{ETI}$, determination.

As in previous experiments the $\mathrm{X}$ 60-X group had a mean $\mathrm{ETI}_{5}$ value at or slightly below that of the previous low point, $\mathrm{ETI}_{4}$. Eight of these rats $(80 \%)$ had a lower value on $\mathrm{ETI}_{5}$ than on any earlier ETI determination.

During Phase 2 the DC group had a sharp increment on Day 1 of Block 1 (one DC trial) and by Day 2 (after three DC trials) was close to the upper limit. The 1-60-1 group showed a gradual increase, and the $\mathrm{X}-60-\mathrm{X}$ group, a slight decrease. The ETI values for the preblock day, the five days of Block 1, and the one postblock determinations were:

\section{D-60-D:}

$70: 151, \quad 199,200,200,203 ; 205$ 1-60-1:

$74: 79, \quad 94, \quad 96, \quad 101, \quad 109 ; 115$ $\mathrm{X}-60-\mathrm{X}$

$100 ; 96, \quad 95, \quad 91, \quad 93, \quad 88 ; \quad 89$

\section{DISCUSSION}

The results obtained in this experiment with the 1-60-1 and X-60-X groups were similar to those obtained in previous experiments (e.g., Gaito, 1980a). There was a gradual increase for the former in mean ETI values (but with a sharp decrement on $\mathrm{ETI}_{5}$ ), and a gradual decrease for the latter. In earlier experiments the intensity was specified as microamperes from peak to peak (a complete cycle), a value 2.8 times greater than the RMS measure involved in this experiment. When the differences between each ETI determination are multiplied by 2.8 , the values obtained are similar to those present in previous experiments. For example, the $38 \mu \mathrm{A}$ (RMS) difference between $\mathrm{ETI}_{1}$ and $\mathrm{ETI}_{2}$ determinations for the $1-60-1$ group is equal to $106 \mu \mathrm{A}$ (peak-to-peak). This is approximately the increment noted for the 1-60-1 groups in all experiments conducted so far. The small decrements for the $\mathrm{X}$ $60-\mathrm{X}$ group in this experiment are as expected from previous results.

Likewise, the mean composite score over the three blocks of trials, and within each block of trials, were similar for these two groups to those from previous experiments. The X-60$X$ group had mean values over the three blocks of trials, and within each block, which showed that kindling progression was proceeding; by Block 3 most rats were convulsing. The $1-60$ 1 group had an opposite pattern: The mean remained below the Stage 2 level (10) in mean composite score for all blocks of trials. Within each block of trials, the mean value on Day 5 was always well below that on Day 1 .
Thus, the suppression pattern for the 1-60-1 group in this experiment was similar to that observed in previous experiments. Furthermore, most of these rats had recovered from the suppression effect following the 32 day rest and were convulsing at their previous low threshold value.

The results for the D-60-D group were much different from those obtained with the 1-60-1 group in all dependent variables of concern. The ETI values increased greatly on $\mathrm{ETl}_{2}$ and remained approximately the same through $\mathrm{ETI}_{5}$. Phase 2 results indicated that the major portion of the sharp increase during the first block of trials occurred on the first day after a single DC stimulation. The mean went from $70 \mu \mathrm{A}$ to $151 \mu \mathrm{A}$. Little increase resulted beyond the second day (after three DC stimulations); the mean ETI for Day 2 was $199 \mu \mathrm{A}$. Furthermore, this group never progressed beyond early Stage 1 behavior.

Other significant results were as follows:

1. On Day 1 of the first block of trials (Phase 1), only one rat from the DC group had a non-Stage 1 response. This result occurred after a single DC trial. In contrast, on this same trial, most of the rats in the 1-60-1 group $(80 \%)$ were showing the same response as observed on the previous day during the ETI determination. 
2. During the $\mathrm{ETI}_{2}$ determination, 9 of the 10 rats in the DC group had a Stage 1 response and were not used in Block 2 trials. Only 1 of the 10 rats in the 1-60-1 group showed this effect. Furthermore, the $\mathrm{ETI}_{1}$ value for this rat was $170 \mu \mathrm{A}$, very close to the upper limit of $200 \mu \mathrm{A}$.

3. Most of the rats in the 1-60-1 group $(70 \%)$ recovered from the suppression effect after 32 days of rest, as indicated by the low $\mathrm{ETI}_{5}$ value; the mean for this group decreased by 68 $\mu \mathrm{A}$. No rats in the D-60-D group had recovered. The mean value for this group remained at approximately the same level from the $\mathrm{ETI}_{2}$ to $\mathrm{ETI}_{5}$ determinations.

These results indicate that the DC effect is a sudden one of strong nature occuring after a single DC trial, whereas the $1-\mathrm{Hz}$ stimulation produces a slower, cumulative effect of transient nature. It appears that at the moderate intensities used in our experiment, DC stimulation produces lesions whereas $\mathrm{I}-\mathrm{Hz}$ stimulation does not. There were definite indications of lesions for the DC group in histological analyses and in behavioral responses. The histological analyses and behavior for the $1-\mathrm{Hz}$ group suggested a transient, nonlesion effect. Still one might argue that small lesions were present in this group but were undetectible by the analyses used. In this context, the- behavioral recovery would be explained as due to tissue recovery. However, the decrease for the $\mathrm{ETI}_{5}$ determination value (relative to $\mathrm{ETI}_{4}$ ) was very great for most rats, rendering this explanation quite implausible. Thus, in the final analysis, the data obtained so far in our laboratory tend to indicate a high probability that an inhibitory process is set in motion by the $1-\mathrm{Hz}$ stimulation (Gaito, 1980d). In contrast to the relatively permanent process produced during the $60-\mathrm{Hz}$ stimulation (Goddard et al., 1969; Racine, 1978), this one appears to be transient, dissipating slowly over time and similar to the "after effect" reported by McIntyre and Goddard (1973).

\section{REFERENCES}

GAITO, J. (1976a). The kindling effect as a model of epilepsy. Psychological Bulletin, 83, 1097-1109.

GAITO, J. (1976b). An oscillation effect during sequential alternations of unilateral amygdaloid stimulations within the kindling paradigm. Physiological Psychology, 4, 303306.

GAITO, J. (1979a). Three Hz brain stimulation interferes with various aspects of the kindling effect. Bulletin of the Psychonomic Society, 13, 67-70.

GAITO, J. (1979b). Suppression of $60-\mathrm{Hz}$ induced convulsive behavior by $3-\mathrm{Hz}$ brain stimulation. Bulletin of the Psychonomic Society, 13, 223-226.
GAITO, J. (1980a). The effect of variable duration one hertz interference on kindling. The Canadian Journal of Neurological Sciences, 7, 59-64.

GAITO, J. (1980b). The effect of varying durations of stimulation on the $3-\mathrm{Hz}$ interference effect. Bulletin of the Psychonomic Society, 15, 221-214.

GAITO, J. (1980c). Gradient of interference by various frequencies on $60-\mathrm{Hz}$, kindled behavior. The Canadian Journal of Neurological Sciences, 7, 223-226.

GAITO, J. (1980d). Interference effects within the kindling paradigm. Physiological Psychology, 8, 120-125.

GAITO, J., NOBREGA, J.N., and GAITO, S.T., (1980). Interference effect of $3-\mathrm{Hz}$ brain stimulation on kindling behavior induced by 60-Hz stimulation. Epilepsia, 21, 73-84.

GODDARD, G. V., McINTYRE, D.C., and LEECH, C.K., (1969). A permanent change in brain function resulting from daily electrical stimulation. Experimental Neurology, 25, 295-330.

MCINTRYE, D.C., and GODDARD, G.V., (1973). Transfer, interference and spontaneous recovery of convulsions kindled from the rat amygdala. Electroencephalography and Clinical Neurophysiology, 35, 533-543.

RACINE, R.J., (1972). Modification of seizure activity by electrical stimulation: 1. Afterdischarge threshold. Electroencephalography and Clinical Neurophysiology, 32, 269-279.

RACINE, R. (1978). Kindling: The first decade. Neurosurgery, 3, 234-252.

WADA, J.A., and SATO, M., (1975). The generalized convulsive seizure state induced by daily electrical stimulation of the amygdala in split brain cats. Epilepsia, 16, 417-430. 